\title{
Tres reflexiones éticas *
}

\author{
PEDRO LAÍN ENTRALGO
}

La palabra, la amistad y la enfermedad son los tres ámbitos escogidos por el autor para vertebrar estas tres reflexiones éticas que configuraron las «IV Conferencias Aranguren». En primer lugar, se pasa revista a la compleja interacción que se crea entre un hablante y su interlocutor, la cual es analizada desde un punto de vista moral, destacándose aspectos tales como la persuasión, la sinceridad o la llamada mentira piadosa. Quizá sólo alguien que une a su condición de ensayista el oficio de médico podía recordarnos lo apuntado al final del trabajo, a saber, que junto a las obligaciones de los médicos para con sus pacientes o la de éstos para con aquéllos, no deben olvidarse los deberes del enfermo para consigo mismo, en tanto que sólo ellos pue- den ayudarnos a transcender nuestra enfermedad y a rentabilizarla desde una perspectiva ética. El intrincado problema de la amistad constituye el núcleo y la parte central del artículo, donde se nos habla de la benefidencia como algo enteramente peculiar y sustantivo de las relaciones amistosas. Esta benefidencia representa un plus que, por encima de la benevolencia, la benedicencia o la beneficencia, transforma una relación humana en un vínculo amistoso. Scgún esta tesis, en el terreno de la amistad no basta con dar algo de lo que se tiene o algo de lo que se hace, sino que también se necesita dar algo de lo que se $e s ;$ y en ello consiste la confidencia hecha al buen amigo.

\section{1. ÉTICA DE LA PALABRA}

La emisión oral de una palabra - sólo al lenguaje hablado voy a referirmees, en el sentido más tradicional del término, un acto humano. Hay en él intención y sentido: intención en el hablante, sentido para él mismo y para el oyente. $\mathrm{El}$ acto de hablar, por tanto, comporta libertad y responsabilidad; tiene carácter ético y se halla sujeto al imperativo del deber. Quien habla a otro es responsable «ante» y responsable «de». Responsable ante él mismo, ante la persona que le oye, ante el juez que, llegado el caso, pueda pedirle cuentas de lo que ha dicho, ante el Tribunal de la Historia - «la Historia del Mundo, Tribunal del Mundo», decían enfáticamente los románticos alemanes- $\mathrm{y}$ ante Dios o un sucedáneo de Dios. Más aún: responsable de lo que dice y de cómo lo dice.

* Se ofrece aquî un resumen de las «IV Cónferencias Aranguren» que, organizadas por el Instituto de Filosofia del CSIC, fueron impartidas por el profesor Laín Entralgo en la Residencia de Estudiantes los días 6,13 y 21 de marzo de 1995. 
Pero, a todo esto, ¿qué es la palabra en tanto que hablada, qué es el hecho de hablar? La respuesta puede ser dada desde múltiples puntos de vista. Yo voy a atenerme únicamente al psicológico y social; esto es, a la función del habla en la vida de quien emite palabras y en la de quien las oye.

\section{Función vital del habla}

Clásica desde hace decenios es la doctrina de Bühler acerca de la psicología del habla. Tres momentos le componen: una función vocativa o de llamada, otra expresiva o de notificación y otra nominativa o de representación. I Iablando, el hablante llama, dice y nombra.

Puede llamar el hablante a un quién concreto (a su madre, a un amigo) o a un quién considerado como qué (al camarero para que le sirva una cerveza). El hablante, además, dice, por lo general, lo que quiere decir; casi siempre menos de lo que quiere decir, porque pocas veces lo dicho llega a ser expresión exacta de lo pensado o sentido; en ocasiones, lo que no quiere decir, como tan bien saben los policías duchos en el arte de interrogar, y en todo caso se dice a sí mismo, convierte en palabras algo de lo que de modo consciente o subconsciente él está siendo. El hablantc, cn fin, nombra, da expresión verbal a sus perceptos, sus conceptos y sus fictos.

Plenamente aceptable es este esquema bühleriano, pero también incompleto por varias razones: el hablante ejecuta una acción distinta de las tres mencionadas, que yo he propucsto llamar suasiva; además de actuar sobre el oyente de esos cuatro modos, experimenta pasivamente dentro de sí el sentimiento correspondiente a cada uno de ellos, y además de hablar llamando, diciendo, nombrando y persuadiendo o disuadiendo, habla también respondiendo, ejecuta una acción responsiva.

Por obra de la función suasiva del habla, el hablante persuade (mueve al oyente hacia su opinión), disuade (le aparta de la que hasta entonces tenía) y, si se me permite el neologismo, antisuade (da lugar a una opinión distinta de la suya); tres formas distintas de la acción que básicamente nombra el verbo latino suadeo, y no sería impertinente traducir por «suadir», influir el que habla sobre el sentir del que le oye. En todo caso, la persuasión no debe ser confundida con la convicción. Ésta consiste en la aceptación de lo que demuestra un razonamiento científico o lógico; aquélla, en el asentimiento a lo que sugieren la verosimilitud o el encanto de lo que se dice o la autoridad que se atribuye al hablante. El grado extremo de la persuasión es la fascinación. «La palabra es mágica para quien la escucha», dice la segunda parte de una brillante sentencia de Sartre, y lo es porque no sólo son la razón y la evidencia lo que le mueve.

$\mathrm{Ni}$ siquiera con esta adición al esquema de Bühler queda íntegramente descrita la acción psicológica del habla. Además de su operación ad extra, hacia 
la realidad del oyente, el habla ejerce complementariamente otra ad intra, hacia la intimidad del hablante. Hablando a otro, mi realidad se modifica.

El reverso íntimo de la función vocativa es la función sodalicia (sodalis, el compañero) de la acción de hablar. Llamando a otro pretendo recibir su compañía. El sujeto de la acción de hablar no es meramente el yo del hablante, es el «tú y yo»; el «nosotros» dual -grato o ingrato- que intencionalmente formamos el otro y yo. El empleo expresivo del habla tiene ad intra una función liberadora o catártica. Si mi intención y mi expresión coinciden, diciendo algo a otro me siento más libre; «me desahogo», suele decirse cuando lo que digo actuaba gravativamente dentro de mí. Algo análogo sucede con la acción nominativa: el acto de nombrar una cosa nos depara respecto de ella un sentimiento de posesión; la palabra que nombra tiene una función posesiva. Tal era el fundamento psicológico del «iSésamo, ábretel» de las Mil y una noches, y tal es el de la primera parte de la sentencia de Sartre antes mencionada: «La palabra es sacra para quien la pronuncia y mágica para quien la escucha.» Nombrar adecuadamente es cosa sacral, don de dioses. También la función suasiva tiene un reverso íntimo. Persuadiendo a otro me afirmo a mí mismo, vivo en mí la función autoafimadora del habla.

Además de llamar, decir, nombrar y persuadir, el hablante responde a las preguntas que se le hacen; el habla tiene en tal caso una función responsiva, cuya recta ejecución nos constituye, más directamente que en todas las restantes, en sujetos responsables. Si alguien me pregunta: «iQué hora es?», y yo le respondo: «La una», mis palabras responden «a» (a una pregunta y a un hombre), responden «de" (de la verdad de mi respuesta) y responden «ante» (ante el hombre que me ha hecho la pregunta, si así me lo exige). Toda respuesta lleva consigo responsabilidad: no es un azar que etimológica y semánticamente el término «respuesta» se diga responsum en latín y que los romanos Ilamaran sponsalia al pacto matrimonial.

\section{El mensaje de la palabra}

¿Qué lleva la palabra a quien la oye? ¿Sólo lo que significa dentro de la lengua a que pertenece y consigna el diccionario? Cuando oímos las palabras «madre», «viento" y "nieve», ¿sólo nos traen la noción de la respectiva realidad a que en nuestro idiona aluden?

No sólo. Tomo de un artículo de García-Sabell esta sutil precisión de Nietzsche: «Al que la oye, una palabra le lleva música, pasión y referencia a una persona.» La música inherente a su sonido, la pasión propia del sentimiento que ese sonido y su significación susciten, y la referencia a una persona, la del que la pronuncia, la del que la oye y la de aquel de quien se habla, si tal es el caso. 
Enlazando el sentido de esta frase de Nietzsche con cuanto acerca de la función vital del habla se ha dicho en el apartado precedente, es posible discernir en el esencial carácter ético de la palabra dos momentos complementarios entre sí:

1..$^{\circ}$ Un imperativo impersonal, el relativo a la verdad de lo que se dice cuando se nombra o se comunica algo, se intenta persuadir o disuadir de algo, o se responde a una pregunta que nos han dirigido: ética de la verdad.

$2 .^{\circ}$ Un imperativo personal, el concerniente al respeto que por razón de lo que esencialmente somos, personas, exige la realidad de quien me oye, mi propia realidad y, si tal es el caso, la de aquel a quien se alude en lo que se dice: ética del respeto.

Estudiemos por separado estos dos momentos de la eticidad de la palabra.

\section{Ética de la verdad}

La verdad como imperativo moral. Enunciado que obliga a preguntarse por algo que ineludiblemente plantea: qué es la verdad.

Centenares de páginas han sido escritas a lo largo de la historia para responder a esa pregunta. Sería aquí impertinente intentar resumirlas. Me contentaré con distinguir muy sumariamente los tres aspectos fundamentales de la verdad:

1. ${ }^{\circ}$ Verdad del razonamiento: la verdad lógica. Sea cualquiera la indole de su contenido, una proposición lógicamente formulada puede ser lógicamente verdadera, con la posibilidad de que, si las premisas son falsas, la proposición sea realmente falsa, lógicamente falsa, por ser torpe o crrónco cl razonamiento que a ella ha conducido, y moralmente falsa, cuando por parte de su autor ha habido mala fe en la formulación de las premisas o en el proceso del razonamiento. De las tres posibilidades ha habido ejemplos en la historia del pensamiento y hay en la vida cotidiana. Consiguiente norma ética: exquisito cuidado de que las premisas del razonamiento no sean falsas, pulcra evitación de toda falacia, sea ésta inconsciente y habitualmente cometida - piénsese, por ejemplo, en la llamada «falacia naturalista»- o, lo que moralmente sería mucho más grave, habilidosamente urdida por el locuente.

2. ${ }^{\circ}$ Verdad de una tesis relativa a la realidad de lo que se hable: la verdad cientifica y la verdad metafisica. En uno y en otro caso, aunque con matiz diverso, to que entra en juego es la verdad real de la tesis que se propone. Una tesis científica tenida por verdadera es en sí misma falsable, en el sentido de Popper, y siempre puede ser rechazada como falsa por la investigación ulterior; así lo fue, valga como ejemplo notorio, la teoría química del flogisto. Otro tanto puede decirse de las tesis metafisicas, aunque -como sucedió con la doctrina aristotélica de las «formas sustanciales»- durante siglos y siglos tal doctrina haya sido considerada necesaria y verdadera. 
Lo cual, tanto en el caso del saber científico como en el saber filosófico, obliga a distinguir cuidadosamente la falsedad y la mendacidad. Hayan sido verdaderos o falsos los saberes enunciados por tal científico o tal filósofo, yo pienso que, salvo muy raras excepciones, el científico en tanto que científico y el filósofo en tanto que filósofo -en uno y en otro caso quiero subrayar tal salvedad - no son mendaces. Stahl y sus seguidores creyeron de buena fe en la realidad del flogisto, y Linneo y los suyos en la fijeza de las especies vivientes, como los extremados realistas medievales en la realidad de las ideas universales. Con su geocentrismo, Ptolomeo incurrió en error, no en falsedad culposa; no mentía. La mentira es siempre delito de lesa verdad; el error sólo $-y$ en menor cuantía - cuando no se ha hecho lo suficiente por evitarlo.

3. La verdad psicologica, esa a que se refieren las expresiones mi verdad y $t u$ verdad, en tanto que manifiestan reserva o distanciamiento del hablante respecto de la verdad. Hay ocasiones en que la verdad psicológica puede ser simplemente crrónca o parcial respecto de la verdad rcal. En cualquier caso, siempre podrá aplicársele el poemilla aforístico de Antonio Machado:

\section{¿Mi verdad? No, la verdad, y ven conmigo a buscarla. \\ La tuya, guárdatela.}

Lo cual no excluye en el oyente el deber de preguntarse si la expresión «mi verdad» tiene algún fundamento real. Deber del locuente: que mi verdad - su verdad - coincida lo más exactamente posible con la verdad, en la medida en que ésta sea conocida. Deber del oyente: juzgar responsablemente acerca de esa mi verdad del locuente; por tanto, conociendo lo que sobre esa materia seriamente se sabe.

\section{Ética del respeto}

El respeto -así traduzco en este caso la palabra alemana que Kant emplea: Achtung - es el nervio y la forma primaria del deber frente a otra persona, en tanto que persona. Si el hombre es res sacra, como dijeron los romanos, respetarle según esa genérica sacralidad suya es nuestra primera obligación ante él. No se trata, por supuesto, del «respeto social» que su situación en la sociedad exija. El a veces demagógico decir popular: «Nadie es más que nadie» es una verdad de carácter metafísico y religioso, no de índole psicológica, ética y social, porque hay hombres más inteligentes, más sabios, más virtuosos y socialmente más dignos que otros, y así debe reconocerlo la relación con ellos. Ni tampoco de un "respeto humano», en el sentido que a la expresión "por respetos humanos» suele darse. El respeto de que hablo es «personal», ese que sólo por serlo merece una persona. Cuando al hablar quiere tenerse en cuenta la tácita o expresa referencia de lo que se dice a una persona deter- 
minada - la del que habla, la del que oye, la de aquel de quien se habla-, ese respeto es la regla. Todo hombre debe respetarse a sí mismo y respetar a los demás.

La ética del respeto en la acción de hablar comprende dos deberes complementarios: uno respecto de la verdad de lo que se dice, el respeto a la dignidad de la verdad; otro respecto del modo como se dice lo que se dice, el respeto al decoro en el decir.

Hay verdades objetivas empíricamente incuestionables (que la nieve sea blanca, que luzca el sol o que llueva) y verdades objetivas racionalmente cognoscibles (que en los procesos físicos sea cumplido el segundo principio de la termodinámica). Puesto que no conciernen a una persona determinada, su enunciación queda ajena al imperativo del respeto. Expresiones tópicas como «la verdad desnuda» o «la pura verdad», en ellas tienen su campo de aplicación. Pero siendo objetivamente incuestionable su verdad, el hecho de que una persona esté gravemente enferma o de que comete faltas de ortografía, ¿podría ser aceptada la regla de «la verdad desnuda» o «la pura verdad», cuando a csa persona o de esa persona se habla? En modo alguno. Si necesariamente hay que aludir a la verdad objetiva que expresan, tanto estética como éticamente será necesario vestir su verdad de un decoroso indumento. Así lo exigen una ética y una estética de mínimos.

Doble mandamiento, contra el cual no sólo se peca por malignidad, también por zafiedad. El tan frecuente desprecio del buen decir, tantas veces acompañado de regodeo en el mal decir - en suma, la consciente agresión a la corrección del idioma-, comporta una responsabilidad ética, aunque no se puede llevar ante un tribunal al que en ella incurre. Tanto más, si en la agresión contra el buen decir va implicada la referencia a una persona determinada. Hace algún tiempo cierto sujeto ejerciente do un cargo político de algún relieve decía públicamente de otro: «iÉste, que ya no puede presumir ante su mujer, quiere ser ahora el que mee más lejos que el vecinol» Oyéndole, iqué habrian dicho el romano que acuñó el res sacra homo y el Kant del imperativo categórico, para no hablar del autor de uno de aquellos ingenuos tratados de urbanidad en que nuestros abuelos se educaban!

Presente o ausente una persona, amiga o enemiga, la referencia a ella exige vestirla de un modo ética o estéticamente decoroso. La supresión del insulto, e incluso de la expresión hiriente, deberían ser regla en la conducta social de aquellos para quienes la palabra uética» es algo más que el nombre de una asignatura o la ocasión para la denuncia de la conducta ajena. Hablando de un paciente suyo afecto de cretinismo, decía un médico: "Es un cretino.» $Y$ temeroso de ser mal interpretado anadía: «En este caso, esta palabra no es un insulto, es un diagnóstico.» Hablando de otra persona, icuántos sabemos distinguir con nuestra conducta entre el insulto y el diagnóstico?

Pero suprimido lo hiriente, ihabrá de ser todo verdad, sólo la verdad y nada más que la verdad cuanto después de csa supresión quede en la palabra 
hablada? Si se trata de hechos cometidos e imputados, sean propios o ajenos, desde luego. ¿También cuando el hecho no es el resultado de una acción (que una persona haya dicho esto o lo otro) o la percepción de algo exterior (que un objeto sea blanco o negro), sino una afección íntima (que esté triste o angustiada la persona a quien o de quien se habla)? En este último caso, ¿estará justificada la mentira, esa a la que suele llamarse «piadosa»?

Delicados problemas, entre los que descuella el que plantea la actitud del médico ante el paciente cuya enfermedad lleva consigo, más o menos próxima y amenazadora, riesgo de muerte. Ésta es mi respuesta: el médico debe decir al enfermo toda la verdad que éste sea capaz de soportar sin trastorno. La diferencia que a tal respecto existe entre el paciente norteamericano y el paciente latino es bien conocida: aquél exige conocer la peligrosidad de su estado, éste la teme, y tal hecho debe condicionar la conducta del médico. Se dirá que esa fórmula requiere un dato diagnóstico no fácil de obtener: la evaluación de la capacidad del enfermo para soportar sin daño la verdad acerca de su estado, si éste es amenazador. Muy cierto. Pero un médico para quien sus pacientes sean personas que sufren una enfermedad, no máquinas cuyo funcionamiento se halla accidental y patológicamente alterado, es seguro que sabrá resolver acertadamente ese problema. Sin la solemnidad de la frase de Sartre antes citada, con su condición de «buen médico» la estará cumpliendo.

Puesto que soy locuente en acto y estoy hablando de la ética de la palabra, terminaré con el recuerdo de una anécdota, cuyo protagonista es Max Scheler, y que por tradición oral se conserva en la Universidad de Colonia. En un seguimiento de su cátedra, disertaba el gran filósofo acerca de los fundamentos de la vida moral, y lo hacía con la sutileza y la profundidad en él habituales. En esto sonó el teléfono en el despacho contiguo, salió Scheler para atender a la llamada, dejó por descuido entreabierta la puerta, y los asistentes al seminario pudieron oír sin dificultad la parte scheleriana de la conversación: «Sí, sí... Dentro de una hora estoy ahí... Si es posible resérveme usted la rubia del otro día.» Volvió el profesor al seminario. Un devoto frailecico asistente a él no pudo contenerse, y con una mezcla de timidez y osadía le dijo: «Profesor, estoy consternado. ¿Cómo es posible que después de lo que tan sugestivamente venía exponiendo hayamos oído lo que por teléfono le acabamos de oír?» A lo que Max Scheler, muy dueño de la situación, respondió así: "Al viajar por carretera habrá visto usted, querido joven, postes indicadores que dicen: A Bonn, tantos kilómetros. Esos postes indicadores, ¿van hacia el sitio que indican? No, ¿verdad? Desde luego, se quedan donde están. Pues así soy yo: digo hacia donde ir si se quiere llegar a ese sitio, pero no paso de ahí.»

He hablado de la ética de la palabra. Si por torpeza mía no la he usado conforme a lo que la palabra exige del hablante, no imitaré esta vez a mi admirado Max Scheler. Me limitaré a decir: mea culpa. 


\section{II. ÉTICA DE LA AMISTAD}

Ante todo, una noción precisa de la amistad. La amistad no es camaradería, ni fruto de la simpatía social, ni relación de tertulia, ni projimidad, ni enamoramiento. A nadie costará gran trabajo advertir la diferencia entre ellas y todas estas otras formas de la relación interhumana. La amistad es una forma particular del amor in genere, entendido éste como sentimiento que mueve a procurar la perfección o el bien de una cosa, una obra humana o una persona, y en este último caso, a convivir como propias la fruición, la perfección o el bien que esa acción haya deparado a la persona amada. Amistad, en definitiva, es una especificación del amor in genere, en la cual la relación entre dos personas, en tanto que tales, se manifiesta como benevolencia, benedicencia, beneficencia y benefidencia mutuas, y que se perfeccionan cuando a esas cuatro acciones se unen la camaradería, la mutua simpatía o el enamoramiento.

En consecuencia, según esos cuatro momentos estructurales de la relación amistosa debe ser examinado su aspecto ético.

\section{Ética de la benevolencia}

La benevolencia para un hombre cualquiera - querer su bien sólo por el hecho de ser hombre- es una virtud más valiosa, sin duda, que la benevolencia amistosa, querer el bien del amigo por ser quien es, por ser «mi» amigo, pero distinta de ella. El Samaritano de la parábola quiso el bien del herido con que se encontró en su camino, fue su prójimo, pero no puede decirse que hasta entonces fuese su amigo; acaso comenzó a serlo cuando se despidieron. Projimidad no es por sí sola amistad, aunque puede convertirse en preámbulo suyo.

Un problema ético previo; amistosa o no, thay en la benevolencia cierto egoísmo? En cierta medida sí, porque si uno es buena persona, querer el bien de otro siempre es grato; uno quiere ese bien porque él es buena persona, desde luego, mas también por la satisfacción de sentir que lo es, siquiera intencionadamente. Pero si el otro no es amigo, y sin dejar él de ser socialmente «buena persona», icumplirá siempre el deber de la benevolencia? No. Con frecuencia se preguntarâ: «ŁłPor qué he de querer yo el bien de cse fulano? Con no desearle el mal cumplo.» No, no es cosa tan frecuente ser íntimamente «buena persona».

Según lo dicho, la benevolencia amistosa lleva consigo el deseo, la bienandanza y la perfección del amigo. Dos cosas es preciso distinguir en el cumplimiento real de esa pequeña virtud, según el amigo esté presente o ausente. Al menos, en el caso de ser cierta la pesimista afirmación de esta sentencia de Antonio Machado: 


\section{Tengo a mis amigos \\ en mi soledad. \\ Cuando estoy con ellos, \\ qué lejos están.}

Ese sutil pesimismo, icorresponde a lo que en realidad es esa relación interpersonal a que tantas veces se da el nombre de amistad? Sí, cuando tal amistad es la del "querido amigo" con que tantas cartas comienzan. Salvo que uno hile en esa materia tan fino como don Antonio Cánovas del Castillo. Despachaba el gran político su correspondencia dictando respuestas a su secretario Morlesín e inició una dirigida a cierto cacique pueblcrino que le pedía no sé qué recomendación con estas tópicas palabras: «Querido amigo.» Morlesín le interrumpe: «Don Antonio, ¿no le parece excesivo llamar amigo a un sujeto a quien usted ni siquiera conoce?» A lo cual respondió Cánovas: «Observe usted, querido Morlesín, que yo no he dicho $m i$ querido amigo, sino simplemente querido amigo. iAlguno tendrá!» Pero cuando la relación amistosa es verdadera amistad, no, porque el verdadero amigo nunca cstá lejos, aunque no se halle presente o no se esté pensando en él; más aún, aunque en ocasiones su presencia no nos lo muestre como nosotros quisiéramos que fuese en sí mismo y para nosotros.

En cualquier caso, querer el bien del amigo, ejercitar con él la benevolencia, es un deber fácil de cumplir.

\section{Ética de la benedicencia}

Consiste la benedicencia amistosa en decir bien del amigo en cuanto tal amigo. Hablar bien de otra persona que no es amiga y lo merece - por ejemplo, hablar bien de Unamuno los que no fueron amigos suyos- exige el cumplimiento de tres deberes, uno de veracidad, otro de sinceridad y otro de respeto. Recuérdese lo dicho al estudiar la ética de la palabra. Hablar bien de un amigo comporta un cuarto y más delicado deber, un deber de amor.

Tambiên respecto de la benedicencia amistosa hay que distinguir dos situaciones del dicente, según está presente o ausente el amigo de que se trate.

Nada más fácil y grato que hablar bien de un amigo presente. En tal caso, sólo una regla ética habrá que cumplir: no pasarse, no convertir la benedicencia en halago adulatorio. Más difícil suele ser, a juzgar por lo que la convivencia social permite observar, hablar bien del amigo ausente, incluso cuando por él seamos capaces de algún sacrificio. Dijo Montaigne que era amigo de La Boétie "porque él es él y porque yo soy yo». Buena fórmula, en cuanto que subraya el imperativo de la autonomía personal incluso en la relación amorosa; aunque sería mejor si se la completase diciendo: «y porque él y yo somos nosotros», puesto que la consideración de ese nosotros dual debe mostrarse en el bien hablar del amigo ausente. Pero uno se pregunta si esa regla es 
fảcil de cumplir cuando en las conversaciones inter amicos tantas veces se oye hablar con cierto crítico despego de un amigo común entonces presente. Con razón afirmaron Aristóteles y Cicerón que son pocos los amigos verdaderos. Verdadero amigo es el que no estando presente aquel a quien llama su amigo hable bien de él, y no sólo por cumplir el genérico «deber de veracidad y de respeto" que exige el hablar de otro, tambićn por obediencia a ese «deber de amor» de que antes hablé. ¿Cómo? Queriendo de veras hacerlo, nada más fácil.

\section{Ética de la beneficencia}

Amistosa o no, la beneficencia, palabra derivada de bonum facere, consiste en hacer cl bien de otro; término de que tan notoriamente se abusaba al hablar de los viejos «Hospitales de Beneficencia» y se sigue abusando cuando se anuncia una «fiesta benéfica». La beneficencia sólo es auténtica cuando su práctica lleva consigo algún sacrificio, aunque sea mínimo, por parte del benefactor.

Una grave cuestión previa: la conducta del represor, religioso o civil, que impone silencios o castigos para bien del castigado o del silencioso a la fuerza -más precisamente, para lo que por fanatismo cree el represor que es el bien del otro--, ¿puede ser llamada beneficencia? Aunque uno no sea doctrinalmente kantiano, ¿no está éticamente obligado a pensar que el primero de los bienes de una persona, tras el de la vida, es el de la libertad y el obrar en consecuencia?

Rectamente entendida la beneficencia, y limitando la atención a su forma amistosa - querer el bien del amigo no sólo por ser hombre, también por ser amigo-, dos posibilidades deben ser distinguidas en la consideración de su aspecto ético.

La primera concierne a los casos en que hay coincidencia entre lo que mi amigo y yo -hablaré en primera persona, puesto que soy el potencial benefactor que tengo más a mano, dirían a una los vizcaínos Antonio Trueba y Miguel de Unamuno- consideremos «su» bien. Nada más fácil y grato que procurar conseguirlo. Acompañar a un enfermo no porque sea una persona que sufre, que esto también lo hace la enfermera, séalo por profesión o por vocación, sino porque el enfermo es amigo mío, mínima beneficencia amistosa es. Con esa acción en alguna medida colaboro en la consecución de «su» bien, el cual, si se logra, será «nuestro», de él y mío.

Distinto y delicado es el caso cuando no haya coincidencia entre lo que él y yo consideramos «su» bien. Dos distinciones se imponen: la que existe entre el «placer» y el «bien»-viejo problema desde Platón-y la que puede separar, o de hecho separe, entre lo que yo considero «su» perfección, el recto cumplimiento de su vocación personal, y lo que en su conducta veo. Delicado problema. Sostuvo Aristóteles que no es posible la amistad con «el malo». 
Pero ¿hay alguien absolutamente malo? Por tanto, también con los «no buenos» - los no enteramente buenos, ¿quién lo es? - puede entablarse amistad. ¿Cómo? A mi modo de ver, cumpliendo el imperativo del respeto amistoso. He aqui su regla: «Respetar lo que el otro es y parece querer ser, procurando delicadamente que sea lo que a nuestro juicio debe ser», que no será sino el recto cumplimiento de su vocación personal. En todo caso, delicado problema. En cierta medida, mantener viva una amistad es, en efecto, una delicada obra de arte.

Es cierto que en determinados casos la maldad es una indeleble mácula biológica, una mancha para la cual, mientras la terapia génica no lo haga posible, no hay detergente eficaz. Alguna razón tuvieron los psiquiatras ingleses del siglo pasado cuando hablaron de la moral insanity, y alguna tenía en el nuestro el también psiquiatra Julius Lange cuando, bajo el título Verbrechen als Schicksal («Crimen como destino»), publicó las historias clínicas de dos gemelos univitelinos que en el curso de su vida cometieron, independiente uno de otro, delitos más o menos semejantes. Pero la predisposición genética al mal, iimpone inexorablemente la ejecución del mal? No parece lícito afirmarlo. No faltaba la razón a Max Scheler para afirmar que, sea o no empíricamente demostrable, alguna responsabilidad tiene el mundo social en que se formó y vive el malvado para que de hecho haya llegado a serlo. Una ética de la amistad suficientemente exigente y fina no puede ser ajena a esta concepción de la maldad.

\section{Ética de la benefidencia}

Como se dice «confidencia» o «infidencia», ¿́por qué no llamar «benefidencia» al hecho de comunicar algo íntimo a un amigo, tanto para «desahogo» del locuente como -esto es lo esencial- para bien de la mutua amistad?

En la beneficencia uno da algo de lo que tiene (dinero, un objeto, sangre para una transfusión o una víscera para un trasplante, tiempo personal) o algo de lo que hace (una obra o una acción personal, la dedicatoria de un libro propio). Pero ies posible dar algo de lo que se es?

Por supuesto, yo no puedo dar mi ser. Excepcionalmente puedo dar mi vida por otro; pero dar mi vida, iequivale a dar mi ser? Arduo problema antropológico y metafísico. En todo caso, yo puedo dar hecho palabra algo de lo que íntimamente soy o estoy viviendo - sentimientos, creencias, amores, opiniones, csperanzas, temores, dudas...-, y en esto precisamente consiste la confidencia, el hablar «de mí para ti»; la cual se hace genuina benefidencia cuando el confidente es amigo, cuando el hacerla no es mero «desahogarse» de algo cuya retención nos agobiaba y de lo que así nos liberamos. Lo cual, por otra parte, muestra la diferencia existente entre ella y la confesión ante el sacerdote o ante el juez: la confidencia está, como dice Le Chevalier, «dentro del pudor», mientras que la confesión está «más allá de él». 
Hecha benefidencia, en la confidencia tiene su ápice íntimo la relación amistosa. Sin ella, sólo con benevolencia, benedicencia y beneficencia amistosas, puede haber, es cierto, amistad verdadera, pero con ella y sólo con ella alcanza la amistad su perfección, su «guinda», como con metáfora de repostería suele hoy decirse. Un «de mí para ti» o un «esto, entre los dos» son las expresiones que tópicamente coronan la pequeña obra de arte que es el recto ejercicio de la amistad.

La confidencia amistosa tiene un contenido, una génesis, un mecanismo, modos y grados distintos, y sobre la base que todos estos momentos de su estructura le ofrecen, debe ser obediente a ciertas reglas éticas.

Contenido: desde el guiño confidencial y el simple intercambio de datos personales con quien empieza a ser amigo, hasta el «para ti no quiero tener secretos» que suscita el verdadero enamoramiento, aquel $\mathrm{cn}$ que se funden cl eros y la amistad; la confidencia de Ingrid Bergman a Humphrey Bogart antes de su despedida en Casablanca, si se quiere un ejemplo notorio.

Génesis: en ella se combinan un impulso impersonal a la elocución (bonum diffusivum sui, decían los medievales; «quisiera ser hombre para poder decir a voces lo que en mí siento», escribió Santa Teresa) y la personal voluntad de comunicación con el amigo que uno tiene ante sí (la de Don Quijote ante Sancho cuando no quiere tratarle como escudero, sino como amigo).

Mecanismo: el resultante de la fusión entre la concreencia (el hecho de que los amigos mutuamente se crean) y la creencia compartida (el hecho de que tengan alguna creencia común, lo cual supone la posibilidad de una relación amistosamente confidencial entre personas creencial o ideológicamente discrepantes). "Quiero que seas una mesma cosa conmigo», dice Don Quijote a Sancho cuando como amigo quiere hablarle.

Modos y grados: desde lo trivial (un juicio personal acerca de tal o cual persona) hasta lo que para uno es grave y profundo (la confidencia tocante a un amor oculto o al modo de sentirse o no sentirse religioso). A veces, sin palabras: una mirada silenciosa puede ser el vínculo confidencial más profundo.

Dice una copla andaluza:

Dijo la lengua al suspiro:
échate a buscar palabras
que digan lo que yo digo.

Sutil ponderación del sonido inarticulado, en tanto que medio de comunicación interpersonal, a la que puede ser añadida esta otra:

Dijo al suspiro el silencio:

yo digo lo que tú quieres

decir, y no estás diciendo. 
De todo lo cual es fácil deducir las dos más esenciales reglas éticas de la benefidencia. Una tocante a la intuición: que el término intencional de ella sea a la vez un «para ti» y un «para nosotros», y no mero desahogo de algo que actúa gravitativamente en la intimidad, porque en tal caso el amigo quedaria convertido en mero receptor impersonal. Otra relativa al contenido; que éste, a fuerza de ser sincero y claro, no hiera la susceptibilidad o la delicadeza del confidente. Un poema de Jorge Guillén expone magistralmente esta segunda regla:

\author{
Amigo: no querrás que te confie \\ todo mi pensamiento, \\ porque te dolería inútilmente \\ cruel veracidad. \\ Simple rasguño hiere al delicado. \\ Una sola palabra acabaria \\ con la dulce costumbre \\ de entendemos hablando entre fricciones \\ evitables, silencios. \\ Ocurre a veces que algún alma clara \\ sin dolor no podría oscurecerse, \\ y resiste y se opone a la tan intima \\ discordia entre vocablo y pensamiento. \\ «Verdad a toda costa». \\ ¿Lujo quizá imposible? \\ El vivir cotidiano es más complejo \\ que la verdad, acorde simplicísimo. \\ La sutil, la dificil vida impura \\ va con el corazón. Vivamos, hombres, \\ y aquí, ¿Drama fatal? \\ Querido amigo...
}

Recuérdese lo dicho sobre la «verdad desnuda» y el «indumento de la verdad» al hablar de la ética de la palabra.

\title{
Amistad y camaradería
}

Consiste la camaradería en la cooperación benevolente entre dos o más personas para la consecución de un bien objetivo común a todas ellas: realizar un programa político o una investigación científica, fundar una empresa, etc. La diferencia entre la camaradería y la amistad es evidente. La compatibilidad, y, por tanto, la conciliabilidad entre ellas, también.

Pero el imparable auge del espíritu objetivo en el siglo XIX, y con él la prevalencia de la relación política y social en la realización de la vida humana, 
ha dado lugar a un desplazamiento doctrinario de la estimación de la amistad hacia la cstimación de la camaradería.

Hegel y Marx fueron los máximos representantes de ese cambio. Cuando en la evolución dialéctica del Espíritu la conciencia de sí se haga verdaderamente racional, cuando el Espíritu objetivo llegue a realizarse plenamente en el Estado - dice Hegel en su Filosofia del Derecho-, entonces el «contenido de mi unidad con los otros hombres será racional y general», no sólo subjetivo. Por su parte, Marx, cumpliendo metódicamente su propósito de ser hegeliano poniendo boca abajo el pensamiento de Hegel y dando contenido marxista a la concepción del Estado perfecto, así entenderá la situación del individuo en la sociedad. Para Marx, sólo la relación conyugal puede y debe ser amorosa sensu stricto. En suma: el prójimo y el amigo deben ser sustituidos por el camarada. Muy bicn expresa esta convicción el revolucionario Stepan en el drama Los justos, de Camus.

Y muy bien da Nietzsche tajante respuesta a esa concepción de la relación intcrhumana en Así hablaba Zaratustra. «Hay camaradería. iOjalá un día haya amistad!», dice, y páginas más tarde añade:

\section{iAl amigo espero, dispuesto dia y noche! iA los amigos nuevos! iVenid, venid, ya es tiempo!}

Nietzsche auguraba deseosamente la llegada de una situación histórica en la cual la amistad sea también camaradería y la camaradería también germen de amistad. O bien, concibiendo la amistad en los términos antes propuestos, entenderla añadiendo a la benevolencia, la benedicencia, la beneficencia y la benefidencia amistosas un elemento nuevo: una cooperación, la que sea, entre las mil y una posibles, en la procura del bien de la sociedad en que se existe, la camaradería.

Creo que esta integral realización de la amistad no es hoy infrecuente, pese a cuanto acerca de la incomunicación como nota distintivà de nuestra situación histórica se ha dicho estas últimas décadas, y pienso que en el empeño de lograrla tiene la ética de la amistad su más importante mandamiento.

\section{III. ÉTICA DE LA ENFERMEDAD}

Puesto que hay modos buenos y modos malos de enfrentarse con la enfermedad, ¿qué es ser buen enfermo? Interrogación que presupone la respuesta a otra, provia a ella: respecto del padecimiento de una enfermedad, bexiste algo que tenga verdadera razón de ser en la consideración ética de la conducta humana, puede haber «deberes» en el enfermo en tanto quc enfermo?

Para responder con algún rigor intelectual a estas dos preguntas creo necesario un inicial planteamiento histórico del problema. 


\section{El hombre ante la enfermedad}

De un modo u otro manifiesta la enfermedad —-dolor físico, vértigo, fiebre, limitación de las posibilidades en la realización de la vida...-, el sentimiento básico de padecerla es siempre el sufrimiento. Y así considerada, la actitud ante ella ha adoptado en la historia tres sucesivos modos cardinales, el castigo, el azar y la prueba.

I. En el período arcaico de todas las culturas - de modo minoritario y supersticioso hasta hoy mismo - la enfermedad ha sido entendida como castigo de una transgresión de la ley religiosa o moral.

1. El Poema del Justo Doliente en la cultura asirio-babilónica, la actitud de los amigos de Job ante la enfermedad de éste y la pregunta de los discípulos de Jesús ante el ciego de nacimiento - «Maestro, iquién ha pecado para que este hombre esté así, él o sus padres?»- en la de Israel, muestran con toda evidencia la realidad de esa concepción de la enfermedad en el mundo semítico. No menos evidentemente la atestiguan, en cuanto a las culturas indoeuropeas, el relato de la peste del ejército aqueo en el Canto I de la Ilíada, la atribución de un carácter kat' anánken, "por invencible necesidad de la naturaleza», a ciertas enfermedades, la kátharsis contra la peste de Tebas de que se habla en el Edipo rey y un texto de Platón (Fedro, 244 a-e) relativo a la génesis de ciertas enfermedades familiares.

La consideración de la enfermedad como castigo de los dioses o como imposición de un fatum inapelable era comúnmente aceptada en el pueblo en el período arcaico de todas las culturas. Pero cuando en el seno de ellas fue surgiendo en algunos la conciencia de la propia personalidad, en ninguna faltaron individuos que de un modo u otro se preguntaron: «Si yo he cumplido fielmente la ley divina, ¿por qué padezco esta enfermedad, por qué sufro?» El Justo Doliente asirio, el judío Job y el Filoctetes griego - no se entendería en su integridad la significación histórica de la tragedia griega si no se viese en clla, como uno de sus momentos esenciales, una rebelión (Antigona, Filoctetes, Ifigenia...) ante el dolor no merecido - dan testimonio fehaciente de esa novedad, tan decisiva para el curso ulterior de la vida humana.

2. Tras la atribución de la enfermedad al castigo de una transgresión de la ley moral aparece en la antigua Grecia la concepción de ella como azar, como evento que se produce pudiendo no haberse producido. Los médicos hipocráticos distinguieron entre las enfermedades kat' anánken, por necesidad forzosa, y las enfermedades katá tykhen, surgidas por azar. Esta segunda interpretación va a prevalecer sobre la primera en el mundo moderno, hasta eliminarla por completo. Por azar se sufre una lesión en un accidente ferroviario, y por azar más o menos científicamente explicable se enferma en el curso de una epidemia. Así entendida, la enfermedad provoca, puras o mezcladas 
entre sí, varias actitudes: la resignación, la desesperación - «ipor qué me ha tocado a mí y no a otro el hecho azaroso de ser víctima de esta epidemia?", se pregunta íntimamente el enfermo- o la incitación a la respuesta activa; el evento azaroso es vivido en tal caso como reto. Desde los hipocráticos hasta hoy, tal ha sido la clave del constante progreso en el tratamiento y la prevención de las enfermedades.

3. No sólo como castigo o como azar ha sido vivida la enfermedad; también como prueba, como ocasional fuente de mérito para la vida en este mundo o para una posible vida personal allende la muerte.

Escribía Basilio de Cesárea a Hilario: «En cuanto a los padecimientos del cuerpo, te exhorto a que te comportes dignamente ante Dios..., pues si Él nos ve recibir las cosas presentes con acción de gracias, o calmará los dolores o las aflicciones, como en el caso de Job, o nos remunerará después de esta vida.» Hasta el tránsito de la Edad Media hacia la modernidad, tópicamente se ha repetido esta actitud en la sociedad cristiana; muy patentemente lo hacen ver textos de San Bernardo y de San Francisco de Asís.

En tal caso, ¿deberá el cristiano desear la enfermedad? Con el auge de la valoración de «lo natural» y de la conciencia de la autonomía de la persona, dos esenciales características de la cultura moderna, rápidamente será revisada esa actitud ante la enfermedad. Así lo hacen ver, ya en el siglo XVI, varios textos epistolares de San Ignacio de Loyola. Entre ellos éste, dirigido al futuro San Francisco de Borja: «No deje enflaquecer la natura corpórea, que siendo ella flaca, lo que es interno no podrá hacer sus operaciones..., porque al cuerpo tanto debemos querer y amar, cuanto obedece y ayuda al ánima.» Pascal, cristiano secular, compondrá una Prière pour demander à Dieu le bon usage des maladies, buen uso tanto hacia la vida transmortal como para la vida en este mundo. El cristiano Novalis, ya a finales del siglo XVIII, advertirá que el «arte para utilizar la enfermedad» falta en la educación del hombre. $\mathrm{Y}$ dentro de la sociedad secularizada, enteramente atenido el hombre a las exigencias, las capacidades y las incitaciones de su naturaleza, icómo no ver que en el logro de prestigio social tiene su principal meta el estoicismo del dandy ante el dolor y la enfermedad?

II. Pero a todo esto, ¿qué es en sí misma la cnfermcdad, cn tanto que noción imprescindible para saber, si enfermamos, cómo debemos conducirnos ante ella?

Tres momentos integran la respuesta:

1. La enfermedad es ante todo un modo aflictivo de vivir. En la mayor parte de los casos -dolor, vértigo, vómitos, embotamiento...- del modo más evidente; mas también cuando podemos sacar de ella algún beneficio; por ejemplo, dejar de cumplir un deber social fastidioso. 
2." En su realidad como accidente en el ser y en la vida del enfermo, la enfermedad es a la vez pathos y ergon, pasión -en el sentido originario y básico de este término: afección pasiva-y operación.

Como afección pasiva, la enfermedad afecta tanto a la cjecución de las funciones vitales (digestión, respiración, etc.) como al sentimiento de vivir, y de ahí su esencial condición de modo de vivir aflictivo (passio como padecimiento).

Como obra del organismo enfermo -más precisamente: de la rẹalidad a la vez somática y psíquica de la persona enferma-, la enfermedad es en sí misma el resultado de una actividad psicosomática; por tanto, operación activa a la vez inconsciente y conscicnte - conscientemente puede un enfermo bronquítico toser más o menos- del organismo personal del paciente. Inconscientemente actúa este organismo en las enfermedades neuróticas strictu sensu - en su forma más simple y primaria, según las dos pautas que en la reacción histérica distinguió Ketschmer, la «tempestad de movimientos» y el «reflejo de quedar como muertom- y el componente neurótico que en todas las enfermedades puede cxistir. Más o menos conscientemente, en el ejemplo antes citado y en la reacción al padecimiento de la enfermedad; como caso extremo, recuérdense las descritas por Kübler-Ross ante el creciente riesgo de una muerte próxima.

La enfermedad, en suma, es a la vez bios, pathos y ergon.

III. Supuesto todo lo precedente, ícuándo y cómo puede y debe ser «buen enfermo» el que padece una enfermedad? ¿En qué puede consistir la ética de la enfermedad, dentro de la actual situación del mundo de Occidente?

La respuesta debe ser dada distinguiendo tres órdenes de deberes del enfermo: ante sí mismo, ante el médico y ante la sociedad.

Los más importantes deberes del enfermo respecto de sí mismo son a mi juicio los siguientes:

1. La aceptación activa y operativa, no meramente pasiva y resignada, de la enfermedad que bien por azar, bien como consecuencia de ciertos hábitos personales, uno está padeciendo. Hans Küng ha dado una excelente fórmula para el cumplimiento de este deber: «No buscar el dolor, sino soportarlo. No sólo soportar el dolor, sino combatirlo. No sólo combatir el dolor, sino transformarlo.» Transformarlo ¿̇en qué? Evidentemente, en vida personal subjetiva y objetivamente valiosa. Ejemplarmente cumplieron este precepto la cristiana Teresa de Lisieux y el ateo Nietzsche. Muy bien lo acredita una carta de éste a su amigo Von Bülow.

$\mathrm{Y}$ en la misma línea se situó Unamuno: «Quien no hubiese sufrido poco o mucho, no tendría conciencia de sí», dice una sentencia suya.

2. Consideración de la enfermedad como un azar susceptible de combate y eliminación mediante la inteligencia y la técnica —es decir, sin la complacencia, 
a la postre viciosa, a que pueden conducir una mala ascética, cristiana o secular-, como prueba para hacer patente la dignidad de la persona.

3. En consecuencia, personalización de la enfermedad, excluyendo radicalmente de la expresión en que tal personalización se manifiesta - decir «mi» enfermedad - la intención de contar con ella para sacar de ella provecho.

4. Voluntad de curación, aunque en ocasiones no sea fácil sentirla. Incluso podrá llegarse a no sentirla en absoluto, como sucede, cuando se intensifican, en los síndromes depresivos.

Hay asimismo en el enfermo deberes para con el médico. Por lo menos, los siguientes:

1. Obediencia no ciega, por supuesto, pero sí razonable: aquella en que rectamente se integren la autonomía personal del enfermo y la obligación de contar con las prescripciones del médico para el logro de la salud, El enfermo es ante el médico una persona con derechos, bien porque personalmente paga sus servicios, bien porque lo hace una institución; el Insalud, en el caso de España. Pcro también con el deber de hacer un uso correcto de ellos.

2. Deber de expresar la verdad sobre sí mismo, cualquiera que sea el médico. La elección del médico por parte del paciente facilita el cumplimiento de ese deber, pero no excluye la obligación de cumplirlo en cualquier otro caso.

3. Abstención en la automedicación, o por lo menos prudencia en su práctica cuando ésta - tomar una tableta de aspirina, recurrir a un laxante- es en principio inocua. Los asclepiadas hipocráticos pensaban que para facilitar el diagnóstico y percibir el tratamiento, el ciudadano culto debe poseer algún conocimiento médico. Así es. Pero la sociedad actual ha ido demasiado lejos en la ejecución de esa regla, y una de sus consecuencias ha sido el abuso de la automedicación, con el consiguiente riesgo para el enfermo.

Deberes del enfermo, en fin, para con la sociedad en que vive. Son los correspondientes al rol social del paciente que el sociólogo Talcott Parsons llama «expectativas institucionalizadas». En el caso del enfermo: el conjunto de deberes que debe cumplir para que la sociedad en que vive le considere «enfermo correcto». Cinco señala Talcott Parsons:

1. Evitar la propagación de su cstado, en la medida en que esto le sea posible.

2. Minimizar las molestias que su estado puede producir a las personas que le rodean.

3. Contribuir cuando le sea posible, con su voluntad de curación y su obediencia al médico, a su pronta integración activa en el grupo social a que pertenezca.

4. Reducir al mínimo las exigencias de orden económico que la enfermedad trae consigo, con especial cuidado si es una institución la que ha de atenderlas. 
5. Si se pertenece a una sociedad opulenta, tener muy presente en su conciencia la exigencia de tantos enfermos que no pueden ser atendidos comoél.

Nietzsche contrapuso el "amor al próximo» del cristianismo al imperativo moral del «amor al lejano»; frente al Liebe zum Nächsten, cl Liebe zum Fernsten. Este último precepto es muy digno de atención; sin él, no habría ayuda a los hambrientos del tercer mundo. Pero la práctica cristiana del «amor al prójimo», ¿puede limitarse a la espacial concepción de éste como «próximo»?

IV. Como conclusión, una pregunta: icuántos enfermos pueden ser considerados «buenos pacientes»? En principio, si en ellos opera eficazmente la voluntad de serlo. Pero icabe desconocer la existencia de «buenas personas» que se resisten a ser «buenos enfermos», cuando la enfermedad les visita? Si tal es el caso, un imperativo ético surgirá para quienes familiar o amistosamente ayuden al doliente: ayudarle delicadamente a hacerse merecedor de tal denominación. 


\section{La balsa de la Medusa}

Número 36

1995

\section{REVISTA TRIMESTRAL}

J. M. Marinas, Retrato de dama con filósofo. P. de Man, La tentación de la permanencia. M. Candel, El gobierno de los mejores. B. Traven, Land des Früblings. C. González-Marín, Iconos. J. C. Rodríguez, Literatura y Filosofia: Deleuze o la caza del Snark. A. SchmidtBurkhard, Breton en la consulta de Freud. La desilusión de un encuentro. D. G. Torres, Marcel Duchamp vs. Stéphane Mallarmé. V. Bozal, Paul Cézanne: La mirada es el lenguaje. E. Romero, Relevancia, inferencia y comunicación. E. Torrego, Noam Chomsky. Lenguaje y pensamiento. J. Arnaldo, Una bistoria cultural de los quince años iniciales del franquismo. M. ${ }^{a}$ I. Peña Aguado, De la sonrisa o de un remedio para la Filosofia.

\section{Edita Visor Dis., S. A. \\ Redacción, administración y suscripciones \\ C/ Totnás Bretón, 55 \\ Teléfono 4681102 \\ 28045 MADRID}

Precio del ejemplar, 800 pesetas. Precio número doble, 1.600 pcsetas. Suscripción anual (4 números): España, 2.900 pesetas. Europa, 4.000 pesetas. América, 4.500 pesetas. 